\title{
Research and Analysis of Mechanical Properties of Fiber Recycled Concrete
}

\author{
Xiangyin Meng, Xiaoyi Quan and Shimin Zhang \\ College of Civil Engineering,Xijing University,Xi'an,China 710123 \\ 1032948067@qq.com
}

Keywords: Stress strain; Tangent modulus; Failure form; Toughness

\begin{abstract}
In order to study the fiber material on the mechanical properties of recycled concrete, based on PPF-1, PPF-2 and RSF-1 containing three fiber replacement rates were 30\% and 50\% recycled concrete specimens were studied. The results show that recycled concrete specimens containing fiber and ordinary concrete failure form of specimens is basically the same however, fiber to improve the toughness of RAC, especially PPF-1 and the toughening effect of PPF-2 is better than RSF-1; for the tangent modulus, not adding fiber linearly, while adding fiber was decreased but more discrete, established fiber recycled concrete stress-strain, mathematical study of stress - the tangent modulus, and provide a reliable basis for the practical application of better fiber recycled concrete.
\end{abstract}

\section{Introduction}

With the development of economy, infrastructure has been put into practice, and all kinds of buildings have sprung up. However, facing the increasingly scarce resources of building materials, the development and research of new building materials has become the focus of social attention. The emergence of recycled concrete (recycled aggregate concrete for short) provides a new approach to the recycling of resources, [1], for the recycling of resources. A series of physical measures such as crushing, washing and so on are used to make aggregate, and the concrete mixed with cement and so on is called recycled concrete.

Due to the large number of micropores and micro cracks [2] in recycled concrete, a lot of researchers have added fiber materials to recycled concrete to enhance the performance of recycled concrete, and achieved good results. Chen Aijiu, Wang Jing [3], by analyzing the performance of recycled concrete test of polypropylene fiber with the fiber, the category is the main factor affecting the recycled concrete flexural strength and splitting tensile strength; Wang Zhenshuang, Tan Xiaoqian [4] of the steel fiber reinforced the basic mechanical properties of recycled concrete, also shows that the steel fiber on the impact strength recycled concrete is small, but significantly enhance the flexural strength of recycled concrete; Liu Huaxin and Yang Jianwei [5] in the regeneration of concrete for many years test experience, summed up the advantages and disadvantages of the influence of raw fiber material concrete. Most scholars have studied the compressive strength, flexural strength and splitting tensile strength of fiber reinforced recycled concrete [6], but little is known about the stress-strain relationship and modulus of elasticity of fiber reinforced recycled concrete. Through the study of polypropylene three branches aging fiber, modified polypropylene fiber and TANK fiber reinforced steel wire meridian rate respectively replace mechanical properties of recycled concrete $30 \%$ and 50\%, and summarize the variation regularity of stress - strain and elastic modulus of the application, in order to better guide students to fiber concrete.

\section{Test}

Test raw materials. The Qinling Mountains cement brand $32.5 \mathrm{r}$ Portland cement, sand the River natural sand, the fineness modulus of coarse aggregate by 2.75 ; service life were 10 years of crushing waste concrete made of natural regeneration; coarse aggregate with continuous gradation crushed stone, and coarse aggregate maximum particle diameter of not more than $31.5 \mathrm{~mm}$. The 
tested concrete is composed of three polypropylene anti aging fibers, modified polypropylene TANK fiber and meridional steel fiber.

Test scheme design. According to "Specification for mix proportion design of ordinary concrete" (JGJ55-2000) of the basic method, in order to study the 3 different fiber content under the replacement ratio is $30 \%$ and substitution rate of the basic mechanical properties of recycled concrete with $50 \%, 6$ in the design group with different substitution rate under different fiber content ratio as the experimental group, to ordinary concrete as the control group, see Table 1, the mechanical properties of recycled concrete to the modification of the. The three anti aging fiber of polypropylene is called PPF-1, and the modified polypropylene TANK fiber is called PPF-2 for short, and the meridian wire fiber is called RSF-1 for short.

Table 1 Basic test mix ratio $(\mathrm{kg} / \mathrm{m} 3)$

\begin{tabular}{cccccccc}
\hline $\begin{array}{c}\text { Type of } \\
\text { concrete }\end{array}$ & Fiber type & cement & $\begin{array}{c}\text { Natural } \\
\text { sand }\end{array}$ & $\begin{array}{c}\text { Natural } \\
\text { lithotripsy } \\
(\text { 0 20mm) }\end{array}$ & $\begin{array}{c}\text { recycled } \\
\text { aggregate }\end{array}$ & water & $\begin{array}{c}\text { fiber } \\
\text { content }\end{array}$ \\
\hline \multirow{3}{*}{ NC } & & 500 & 465 & 1199 & 0 & 215 & 0 \\
& PPF-1 & 500 & 465 & 1199 & 0 & 215 & 0.9 \\
& PPF-2 & 500 & 465 & 1199 & 0 & 215 & 0.9 \\
& RSF-1 & 500 & 465 & 1199 & 0 & 215 & 0.9 \\
\hline \multirow{5}{*}{ RAC-30\% } & PPF-1 & 500 & 466 & 839 & 360 & 215 & 0 \\
& PPF-2 & 500 & 466 & 839 & 360 & 215 & 0.9 \\
& RSF-1 & 500 & 466 & 839 & 360 & 215 & 0.9 \\
\multirow{2}{*}{ RAC-50\% } & & 500 & 466 & 600 & 600 & 215 & 0 \\
& PPF-1 & 500 & 466 & 600 & 600 & 215 & 0.9 \\
& PPF-2 & 500 & 466 & 600 & 600 & 215 & 0.9 \\
\hline
\end{tabular}

NC represents ordinary concrete; HF-RAC-30\% represents a recycled fiber reinforced concrete with a replacement rate of $30 \%$; the same HF-RAC-50\% is a recycled fiber reinforced concrete with a replacement rate of $50 \%$.

Test phenomenon. Figure 1 (a) (d), the damage from the recycled concrete prism with different fiber morphology can be seen: the admixture of recycled concrete fiber PPF-1, PPF-2 and RSF-1 of the failure modes and ordinary concrete damage form is basically the same as [7], are all along the longitudinal diagonal prism specimens were destroyed, but compared with ordinary concrete, the recycled concrete cracks in small containing fibers, and the surface of the dregs of the ordinary concrete without obvious. From Figure 2 (a) (d) can be seen, ordinary concrete and recycled concrete with fiber splitting tensile strength of the destruction from the middle part of the splitting, but the recycled concrete fiber bearing capacity is lower than that of ordinary concrete;

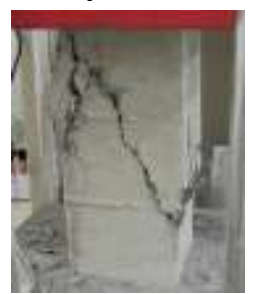

(a) $\mathrm{NC}$

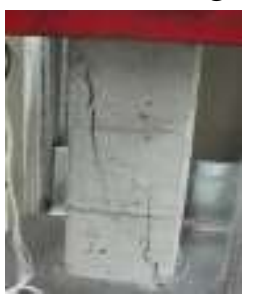

(b) PPF-1

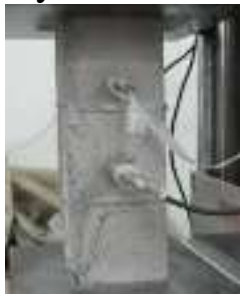

(c) $\mathrm{PPF}-2$

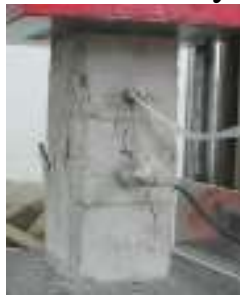

(d) RSF-1

Figure. 1 Prism compression failure diagram 


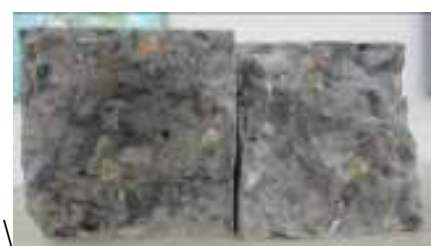

(a) $\mathrm{NC}$

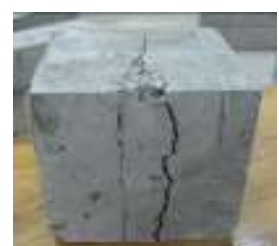

(b) PPF-1

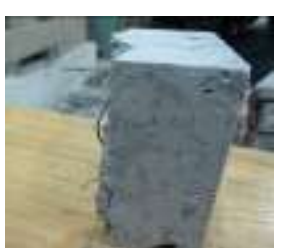

(c) PPF-2

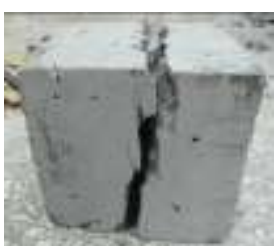

(d) RSF-1

Figure. 2 Fracture diagram of splitting tensile strength

\section{Test results and analysis of mechanical properties}

Strength analysis. The replacement rate of recycled concrete is $30 \%$ and $50 \%$ respectively with PPF-1, PPF-2 and RSF-1 fiber, the cube compressive strength, prism compressive strength, splitting tensile strength and flexural strength were normalized, for different substituted recycled concrete with different fiber ratio the flexural strength is obviously improved, the prism compressive strength, the replacement rate of recycled concrete decreased with PPF-2 30\% under the strength of the other replacement rate under the strength of recycled concrete fiber are improved; the cubic compressive strength, the blending fiber did not have much impact on concrete compressive the strength of basic floating within 5\%; and for the splitting tensile strength of the fiber added recycled concrete overall a larger decline, only the replacement rate of RSF-1 fiber containing 30\% The regenerated concrete and the strength of recycled concrete with the substitution rate of 50\% PPF-1 fiber are improved, but the increase in amplitude is small. And from the strength difference meter 5, it can be seen that the maximum increase in flexural strength is nearly $28 \%$ and the minimum increase is about $11 \%$ after adding fiber. Therefore, the toughening effect of fiber on recycled concrete is better.

Table 2 Strength variation rate $1 \%$

\begin{tabular}{lllllll}
\hline $\begin{array}{l}\text { Substituti } \\
\text { on rate }\end{array}$ & $\begin{array}{l}\text { Fiber } \\
\text { type }\end{array}$ & $\begin{array}{l}\text { Cubic compressive } \\
\text { strength difference } \\
/ \Delta f_{c u}\end{array}$ & $\begin{array}{l}\text { Prism } \\
\text { strength difference } \\
/ \Delta f_{c}\end{array}$ & $\begin{array}{l}\text { compressive } \\
\text { strength } \\
\text { difference } / \Delta f_{t, s}\end{array}$ & $\begin{array}{l}\text { difference } \\
\text { ratio } / \Delta f_{f}\end{array}$ \\
\hline & $\begin{array}{l}\text { PPF- } \\
1\end{array}$ & 1.84 & 9.17 & -5.77 & 14.2 \\
& $\begin{array}{l}\text { PPF- } \\
30 \%\end{array}$ & -4.37 & -14.5 & -15.3 & 18.6 \\
& $\begin{array}{l}2 \\
\text { RSF- } \\
1\end{array}$ & 1.92 & 8.2 & 2.7 & 10.7 \\
& $\begin{array}{l}\text { PPF- } \\
1\end{array}$ & 1.35 & 15.6 & 5.48 & 12.6 \\
& $\begin{array}{l}\text { PPF- } \\
2\end{array}$ & 2.74 & 18.0 & -6.61 & 26.6 \\
& RSF- \\
1 & -2.56 & 3.27 & -11.0 & 27.8 \\
\hline
\end{tabular}

Analysis of deformability.In PPF-1, RSF-1 doped fiber, as the replacement ratio of recycled concrete peak stress does not exceed $30 \%$ of the fiber RAC $9.1 \%$ and $8.3 \%$, but the peak value of RAC doped PPF-2 fiber stress was reduced by 14.5\%; and the replacement rate of 50\% RAC mixed with three kinds of fiber PPF-1, PPF-2, RSF-1 and the stress peak the value exceeded $15.5 \%, 17.8 \%$ and $3.6 \%$

From Figure 3 (b) for elastic modulus normalized figure in doped PPF-1, reduce the amount of elastic modulus of ordinary concrete $3.3 \%$, instead the replacement ratio is $30 \%$ and the elastic modulus of $50 \%$ RAC increased by $20.3 \%$ and $14.8 \%$; when the PPF-2 doped fiber, the elastic modulus of ordinary concrete and recycled concrete replacement rate of $50 \%$ increased by $8.5 \%$ and $14.5 \%$, while the replacement ratio is $30 \%$ RAC decreased $6.1 \%$; RSF-1 doped fiber, the elastic 
modulus of concrete and 50\% replacement rate of recycled concrete decreased by $1.03 \%$ and $2.51 \%$, while the replacement rate of $30 \%$ RAC was increased by $5.7 \%$.

The peak strain as shown in Figure 5 (c) normalized shown: the substitution rate of recycled concrete is $30 \%$ and $50 \%$ of the peak strain contains three kinds of fibers were less than fiber recycled concrete and ordinary concrete, including PPF-2 the replacement rate of 50\% RAC maximum decline of $33.1 \%$. It is known that the deformation of recycled concrete is controlled by the tensile bridging of fiber, but the size of control depends on the type of fiber and the deformation coordination between fiber and cement paste.

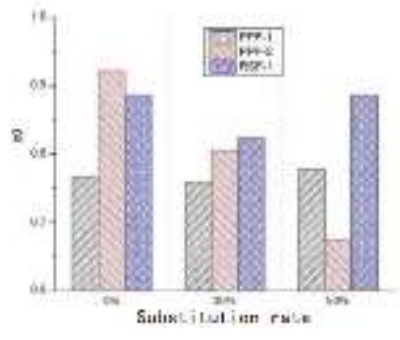

(a) $f_{\mathrm{c}}$

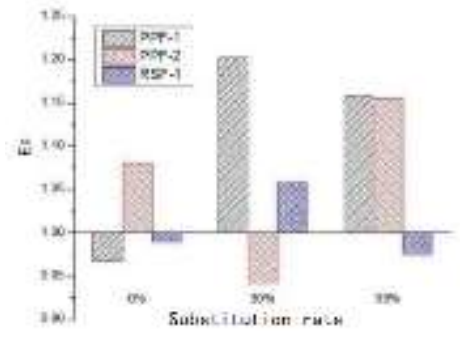

(b) $\mathrm{E}_{\mathrm{c}}$

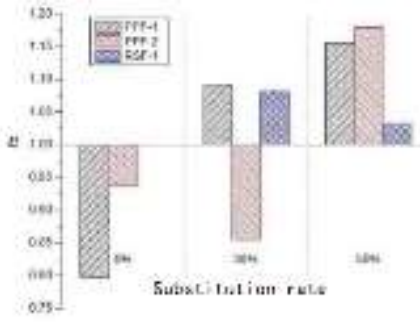

(c) $\varepsilon_{0}$

Figure. 3 Normalization of deformation properties

\section{Summary}

In this paper, the basic properties of three kinds of polypropylene, such as PPF-1, modified polypropylene TANK fiber PPF-2 and meridian steel fiber RSF-1 three different fibers, are studied.

the failure modes of RAC specimens containing fibers are basically the same as those of common concrete specimens. However, the pulling effect of fibers makes RAC exhibit a certain toughness, which effectively improves the flexural strength of RAC, and PPF-1 and PPF-2 have better toughening effect than RSF-1.

learned from the deformation performance of the RAC, the compatibility of deformation deformation control of RAC mainly depends on the fiber type and fiber and cement paste, and study the relationship with different fiber under stress - strain, tangent modulus stress, provide a basis for engineering application.

\section{Reference}

[1] Lv Xilin, Zhang Ying, completed in the year. Experimental research on axial compressive stress-strain curves of steel fiber reinforced high-strength concrete under monotonic and repeated loading [J]. Journal of building structures, 2017, (01),p.135-143.(In Chinese)

[2] Wang Sheliang, Li Tao, Yang Tao, Zhang Bo, mega. Experimental study on seismic behavior of recycled concrete columns filled with silica fume and fiber [J]. Journal of building structures, 2013, (05),p.122-129.(In Chinese)

[3] Chen Aijiu, Wang Jing, poplar powder. Mechanical properties test and failure analysis of fiber recycled concrete [J]. Journal of construction materials, 2013, (02),p.244-248+265.(In Chinese)

[4] Wang Zhenshuang, Tan Xiaoqian. Study on mechanical properties and frost resistance of steel fiber recycled coarse aggregate concrete [J]. Portland bulletin, 2016, (04),p.1184-1187.(In Chinese)

[5] Liu Huaxin, Yang Jianwei, Wang Xuezhi, Liu Genjin. Progress of fiber materials and recycled concrete combination application of [J]. Portland bulletin, 2017, (02),p.507-514.(In Chinese)

[6] Li Sujuan. Experimental study on compressive strength of recycled basalt fiber reinforced concrete [J]. world earthquake engineering, 2016, (02),p. 89-92.(In Chinese)

[7] Guo Hui, deer, Zhang Lijuan, Peng Liang. Orthogonal experimental research on shear performance of steel fiber recycled concrete $[\mathrm{J}]$. world earthquake engineering, 2016, (02),p.107-112.(In Chinese) 
[8] Zhou Jinghai, Li Ze, Kang Tianbei. Simulation study on [J]. fiber waste concrete, two-dimensional distribution of fiber recycled concrete in 2016 (08),p.99-102+106.(In Chinese) 